BULLETIN Bulletin hispanique

HISPANIQUE Université Michel de Montaigne Bordeaux

121-2 | 2019

Representaciones de autor (XV-XIX). Retratos, biografías, polémicas

\title{
Ian Gibson, Los últimos caminos de Antonio Machado. De Collioure a Sevilla
}

Barcelona, Planeta, 2019

Jacques Issorel

\section{OpenEdition \\ Journals}

\section{Édition électronique}

URL : https://journals.openedition.org/bulletinhispanique/9714

DOI : 10.4000/bulletinhispanique.9714

ISSN : $1775-3821$

\section{Éditeur}

Presses universitaires de Bordeaux

\section{Édition imprimée}

Date de publication : 18 décembre 2019

Pagination : 748-749

ISBN : 979-10-300-0507-3

ISSN : 0007-4640

\section{Référence électronique}

Jacques Issorel, « lan Gibson, Los últimos caminos de Antonio Machado. De Collioure a Sevilla », Bulletin hispanique [En ligne], 121-2 | 2019, mis en ligne le 10 décembre 2019, consulté le 06 janvier 2023.

URL : http://journals.openedition.org/bulletinhispanique/9714 ; DOI : https://doi.org/10.4000/

bulletinhispanique.9714

Ce document a été généré automatiquement le 6 janvier 2023.

Tous droits réservés 


\title{
Ian Gibson, Los últimos caminos de Antonio Machado. De Collioure a Sevilla
}

\author{
Barcelona, Planeta, 2019
}

Jacques Issorel

\section{RÉFÉRENCE}

Ian Gibson, Los últimos caminos de Antonio Machado. De Collioure a Sevilla. - Barcelona, Planeta, 2019, 245 p. ISBN-13 : 978-8467055108

1 Le titre, l'étonnant sous-titre, la première des quatre épigraphes («Caminante, son tus huellas / el camino... »), le titre de la section introductive (" Fin de recorrido») indiquent nettement que Ian Gibson a placé son ouvrage sous le signe du chemin. Le chemin comme symbole dans les deux premiers recueils (Soledades, puis Soledades. Galerías. Otros poemas). Le chemin de vie d'un Sévillan qui posera ses valises successivement à Madrid, Soria, Baeza, Ségovie, Madrid encore, pour finalement aller mourir, via Valence et Barcelone, dans un petit port de pêche français, Collioure. Enfin, le chemin d'un intellectuel qui prend conscience, dès trente ans, de la nécessité et du devoir de l'engagement politique ( Yo no puedo aceptar que el poeta sea un hombre estéril que huya de la vida para forjarse quiméricamente una vida mejor en que gozar de la contemplación de sí mismo [...] ¿No seríamos capaces de soñar con los ojos abiertos en la vida activa, la vida militante? », critique de Arias tristes de J. R. Jiménez, 1904, citée par Gibson dans Ligero de equipaje. La vida de Antonio Machado, Ed. Santillana, 2007, p. 176). Ces trois niveaux de lecture s'entrecroisent sans cesse tout au long de ce livre aussi passionnant qu'un (bon) roman. Si ce dernier mot vient s'imposer sous la plume de l'auteur de ces lignes, c'est que, outre le grand chercheur, l'historien rigoureux qu'il est, Ian Gibson est aussi un écrivain, un maître de la langue espagnole.

2 Les chemins machadiens retracés dans ce livre commencent par... la fin ( $F i n$ de recorrido »): Collioure, où, le 22 février 1939, vingt-six jours à peine après être arrivé avec sa vieille mère, Ana Ruiz, son frère José et sa belle-sœur Matea, le poète expire, 
entouré des siens et de quelques amis colliourencs (Jacques Baills, Juliette et Sébastien Figuères); Collioure, où il achève son œuvre avec un vers, un seul, mais magistral: "Estos días azules y este sol de la infancia ».

3 Après cette entrée en matière, Gibson divise l'itinéraire du poète en six grandes étapes : I. «De Sevilla a Soria (por Madrid y París)» [1875-1912]; II. « De Baeza a Segovia » [1912-1931]; III. «Caminos republicanos» [1931-fin 1935]; IV. " Frente Popular, Madrid asediado " [janvier-novembre 1936]; V. «De Valencia a Barcelona " [novembre 1936-janvier 1939]; Le titre du sixième chapitre ( VI. "Cita con Ella») a été inspiré à l'auteur par le dernier vers d'un bref poème de Soledades. Galerías. Otros poemas : «[...] Mas Ella no faltará a la cita ». Gibson y refait avec le poète, les siens et leurs compagnons le chemin vers l'exil dans l'horreur d'un exode massif et désespéré, jusqu'à l'arrivée à Collioure, puis il rappelle ce que furent les derniers jours à l'hôtel Bougnol-Quintana.

4 Les cinq dernières pages font pendant aux cinq premières ("Fin de recorrido") et portent un très beau titre: «España, este dolor ». Dans cet épilogue, on voit Manuel Machado, déjà "todo un personaje en la España de Franco » (p. 203), venir s'incliner en compagnie de sa femme, Eulalia, devant la tombe (provisoire) de son frère et de leur mère, décédée trois jours plus tard. Après avoir rappelé que José et Joaquín Machado et leurs épouses s'exilent définitivement, dès 1939, au Chili, et que leur frère Francisco (" declarado exento de responsabilidades políticas durante su etapa como director de la Prisión de Mujeres de Madrid, su último puesto», p. 204) retourne en Espagne dès la fin de la guerre et retrouve son poste de fonctionnaire, Ian Gibson revient sur la relation qu'Antonio Machado entretint pendant huit ans avec celle qu'il appelait dans ses lettres la « diosa » et Guiomar dans ses poèmes. Là, et plus haut dans le livre (chap. II, III et IV), c'est un euphémisme de dire qu'il n'éprouve guère de sympathie à son égard. Dans la dernière page, en tout cas, il juge "inaceptable[s]» ces lignes écrites par Pilar de Valderrama dans ses mémoires (Sí, soy Guiomar, 1981) : « Yo sé que sin mi ausencia, Antonio no hubiera escrito muchas cosas de las que publicó en Madrid, Barcelona o Valencia durante la guerra; ni hubiera pronunciado algunas conferencias que no eran dignas de él » (p. 207).

Ian Gibson émaille son texte de très nombreuses citations extraites des poèmes les plus connus ou appartenant à des compositions de De un cancionero apócrifo ou encore aux 127 poèmes et groupes de poèmes, répertoriés dans les 0 .C. sous le titre de Poesías sueltas. Toutes sont du plus haut intérêt, car elles mettent en lumière nombre d'aspects, souvent négligés par la critique, de la création machadienne. Les 522 notes regroupées en fin d'ouvrage témoignent de la connaissance exhaustive que possède Gibson de la bibliographie du poète. Il y ajoute les témoignages qu'il a recueillis auprès des filles de José Machado (María et Carmen) et de Leonor, fille de Francisco. La généreuse bibliographie n'occupe pas moins de neuf pages. Enfin, 16 photos illustrent agréablement cet ouvrage, en tous points remarquable, qu'apprécieront autant les vieux machadistes que les jeunes hispanisants. 


\section{AUTEURS}

JACQUES ISSOREL

Université de Perpignan 